Harrower, The Algae Society BioArt Design Lab: Exploring multispecies entanglements and making kin with algae

May 19, 2021

\title{
Title
}

The Algae Society BioArt Design Lab: Exploring multispecies entanglements and making kin with algae

\section{Author List}

Juniper Harrower (Director of Art+Science), Norris Center for Natural History, University of California, Santa Cruz, 1156, High Street, Santa Cruz, CA, 95064, USA.

Email:<jharrower@ucsc.edu>

ORID: 0000-0003-4498-8455

Gene Felice (Assistant Professor of Digital Art), University of North Carolina, Wilmington, 601 S College Rd, Wilmington, NC 28403, USA.

Email: <gf@genefelice.com>

Jennifer Parker (Professor of Art), University of Santa Cruz, 1156, High Street, Santa Cruz, CA, 95064, USA.

Email: <parker1@ucsc.edu>

José Carlos Espinel (Art Lecturer), Universidad Complutense de Madrid, C/ Pintor El Greco, Madrid, 228040, España.

Email:<jcespinel@ucm.es>

David Harris (Lecturer of Design), University of the Sunshine Coast, 1 Moreton Parade, Petrie QLD 4502, Australia.

Email: <dharris2@usc.edu.au>

ORID: 0000-0002-8321-2062

Fiona Hillary (Lecturer of Art), RMIT University, 124 La Trobe St, Melbourne VIC 3000, Australia.

Email: <fiona.hillary@rmit.edu.au> 
Harrower, The Algae Society BioArt Design Lab: Exploring multispecies entanglements and making kin with algae

May 19, 2021

Tiare Ribeaux (Creative Director B4BEL4B gallery), 184 10th St., Oakland, CA, 94607, USA. Email: <tiarenoelle@gmail.com>

\title{
Keywords
}

Art+science collaboration, algae, making kin, environmental art, multispecies, interdisciplinary, BioArt

\begin{abstract}
The Algae Society BioArt Design Lab is a global collective of interdisciplinary researchers working together with algae as non-human international research partners. As a collaborative group of artists, scientists and scholars, they experiment and co-produce with algae, seeking to highlight complex human interdependence and kinship with algal beings. Here they introduce the Algae Society and share a collective collage of their evolving artistic works while reflecting on each researcher's process, materiality, and aesthetic considerations. With these works, they endeavor to shift our perspectives from human-centric exceptionalism to greater appreciation and cultural reframing of our responsibility as participants in multi-species worlding.
\end{abstract}

\section{Text}

Human behaviors are devastating ecosystems with major consequences for algae and other species that will resound through the current and future generations of life on earth ${ }^{1}$. Algae are vitally important to our survival and together we share deeply complex histories of human-algal interactions across cultures and throughout time ${ }^{2}$. For example, algae produce the majority of the oxygen on our planet and help to stabilize ocean and aquatic ecosystems ${ }^{3}$. Conversely, algae can also be toxic to humans and other organisms and may destroy ecosystems during widespread algal blooms increasing in number and severity because of human activities ${ }^{1,3}$. Cretaceous algae deposits comprise a large portion of the fossil fuel industry, through which our destructive practices of extraction and consumption continue to drive climate change and species loss at alarming rates. It is critical that we shift the ways in which we work with algae, and there are many options as we move forward: They can be sustainably produced as an efficient and ethical 
Harrower, The Algae Society BioArt Design Lab: Exploring multispecies entanglements and making kin with algae

May 19, 2021

biofuel $^{2}$, show excellent potential for large-scale sustainable food production, have been highly successful in aquaculture, and produce a useful and sustainable material ${ }^{4}$.

While these practical and critical environmental concerns deserve our focused attention, as art and science researchers at the Algae Society BioArt Design Lab, we are also interested in the process of "worlding" in conscious partnership with our algae "kin" 5 . This is a viewpoint proposed by critical theorist Donna Haraway, which we interpret for our work as theorizing and storytelling that bridges the complex histories and meetings of human and algal species ${ }^{5}$. We seek to decenter human exceptionalism by "making kin" with the more-than-human world. This concept proposed by Haraway asks us to bring considered attention to the various beings with whom we engage in multispecies entanglements. Multispecies relationships that result in significant planetary consequences for all involved ${ }^{5}$. By engaging in the practice of building kinship with algal species, we embrace the symbiotic spectrum of challenges this kinship entails and our responsibilities as active participants within these interactions. We work across disciplines and geographies, aiming to unravel and rebuild new ways of worlding with our algal collaborators that prioritize multispecies justice. As part of our process, we partake in interdisciplinary research with algae and create place-based exhibitions for diverse publics aiming to shift culture towards sustainable practices. While a scientifically informed public is critical to devise solutions and implement approaches that slow environmental destruction, it is only when facts are integrated with emotional connections that people are compelled to make changes $^{6,7}$.

Art is a powerful force for social change, both as an inquiry-based practice and method of meaning seeking and as a platform to share complex environmental issues with diverse publics that can shape culture and influence behaviors ${ }^{8}$. Recognizing this, the Algae Society is an international group of art and science algal researchers that promote interdisciplinary approaches for addressing and reframing current environmental challenges. Some of the questions informing our work include: How might we facilitate successful art and science partnerships that can contribute to ecological knowledge production and species protection? In what ways does art help us to better understand algal ecologies, providing deeper insight into the outcomes of 
Harrower, The Algae Society BioArt Design Lab: Exploring multispecies entanglements and making kin with algae

May 19, 2021

human-algal species entanglements? How can we move beyond human-centered thinking to better collaborate and co-create with our algal kin?

The Algae Society works primarily through the medium of art and science-based exhibitions at museums, galleries, science centers, and community spaces. Our evolving transdisciplinary research hybrids incorporate contributions from scientists and artists working within their specializations while cultivating the fertile spaces between disciplines. Together we collaborate for large-scale public outreach, creating space for problem-solving and community actions for algal stewardship and hands-on engagement opportunities with algal ecosystems at various international institutions ${ }^{9}$. The Algae Society process brings international participants together to discuss and explore current research about algal ecosystems. Scientists share their research, clarify data, and co-act with artists through a shared vocabulary and trust that is built over time. Artists ask explorative questions and transform information through story, metaphor, and abstraction while workshopping engagement strategies with researchers and the public. The codevelopment of interactive media for a global audience results in public installations that aim to aesthetically and emotionally connect us to algae while also promoting environmental stewardship.

The following Algae Society contributions addressing these themes were featured at various international museums and galleries from 2018-2019, including the COP25 climate conference in Madrid, reaching thousands of people. Through this work, we create multimedia bridges for understanding and exploring with algal organisms while sparking curiosity among participants and viewers.

Oceanic Scales by artists Gene Felice and Jennifer Parker engages visitors to explore their role in maintaining a stable ocean ecology through a multi-sensory, interactive art and science puzzle inspired by the microorganisms of the sea (Figs 1 and 2). Oceanic Scales focuses the lens on phytoplankton (a category that is comprised of mostly algae), which are critical organisms to ocean biology and for climate regulation ${ }^{2}$. Phytoplankton are primary producers and are a food source for microscopic zooplankton, fish, and massive whales. These algae also act as an 
Harrower, The Algae Society BioArt Design Lab: Exploring multispecies entanglements and making kin with algae

May 19, 2021

essential carbon sink and regulator of global surface temperatures by transferring carbon dioxide from the atmosphere and storing it in various forms in the ocean ${ }^{2}$. Aiming to bring awareness to our kinship with algae, we immerse the public in a data-driven, interactive ocean ecosystem to reflect on and better understand how we impact these organisms and the environment at local and global scales. Light, scent, sound, and touch inspire new ways of thinking and interacting with ocean health. Developed to illustrate the role of phytoplankton as an essential and interconnected part of our planetary ecosystem, it provokes curiosity through interactive participation by the public, giving visitors the option to experience the work passively or actively. They can absorb its multi-sensory interpretation of ocean data as complex patterns of light and sound, or they can decide to become an active agent of change, trying out various trial and error scenarios by adjusting temperature, $\mathrm{pH}$ and nitrogen levels within the automated gaming system. Instability may lead to a system crash; harmony can be achieved through perceived stability, patience, and new understanding. Through this engagement, we hope to foster empathy and facilitate a new understanding of our responsibility to ocean ecosystems. The creation of the physical structure is also ecologically minded, built with local bamboo plywood and pine resin, corn plastic 3D printed forms, recycled cardboard, natural latex rubber, solar power and a living component of native plant species. Video available at:

http://oceanicscales.com/ 
Harrower, The Algae Society BioArt Design Lab: Exploring multispecies entanglements and making kin with algae

May 19, 2021

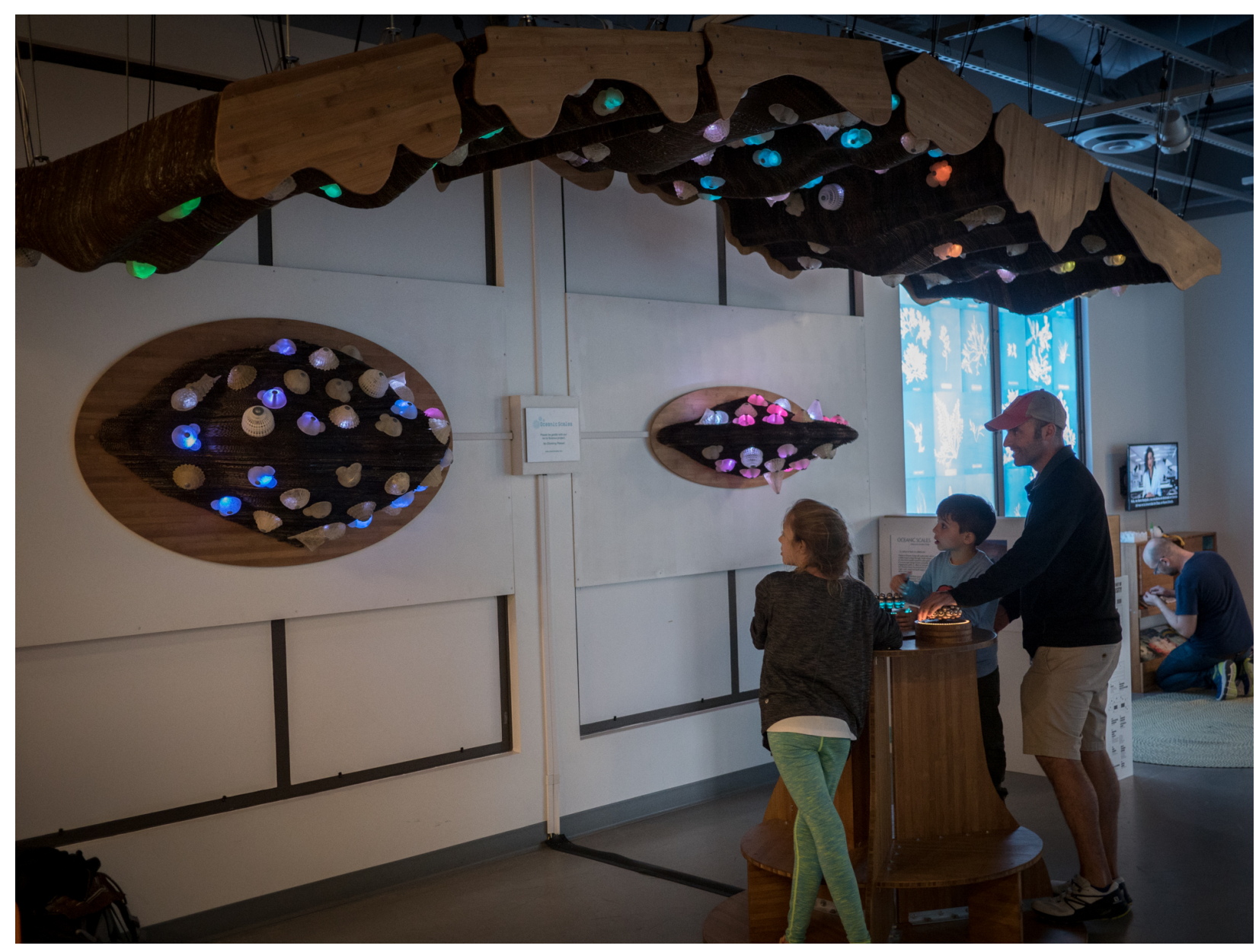

Fig. 1. Oceanic Scales installation view. (@ Gene Felice and Jennifer Parker. Photo: Gene Felice.)

Collaborations with Algae by artist/ecologist Juniper Harrower is a time-lapse performance and exploration in materiality that considers human-algal symbiotic relationships both in the field and the art studio (Fig. 2). Symbiotic relationships can vary widely on a dynamic spectrum from beneficial to harmful outcomes depending on the interacting organisms and the local environment ${ }^{1,2}$. In a healthy aquatic ecosystem, phytoplankton provides food for a wide range of organisms. When too many nutrients become available in the system, phytoplankton may grow explosively and form harmful algal blooms (HABs). These blooms can produce extremely toxic compounds that have harmful effects on fish, shellfish, mammals, birds, and even people. 
Harrower, The Algae Society BioArt Design Lab: Exploring multispecies entanglements and making kin with algae

May 19, 2021

Human activities such as nutrient pollution from urban, rural, and agricultural landscapes, and numerous complications from climate change contribute to a worldwide increase in $\mathrm{HABs}^{2,3}$. Considering these issues, Collaborations with Algae explores the spectrum of symbiosis through a staged interaction. Algae oil and dried algae are collected from different environmental locations and then mixed with paint and water to create a new art medium and then applied to a canvas with a series of movements that are captured by time-lapse photography. This process creates a novel fractioning of the paint as the algae influences the materiality of the work and the physical and chemical behaviors of the paint. These resultant collaborative moments happen within the context of larger aesthetic decisions made by the artist but which are driven by data on algal blooms from the various algae collection locations. Beginning paintings symbolize healthy algal ecosystems, while later works take on the coloration of toxic algal blooms, gesturing to the possibilities of different environmental states under the impacts of human influence. The evolving organic imagery represents both the microscopic algal forms and macroscopic landscape-scale patterns at algal bloom sites reminiscent of satellite imagery. The movements throughout the performance are similar to watching cellular processes unfold or evocative of the action of water vortices. Performance video available to view at https://vimeo.com/371955245. 
Harrower, The Algae Society BioArt Design Lab: Exploring multispecies entanglements and making kin with algae

May 19, 2021

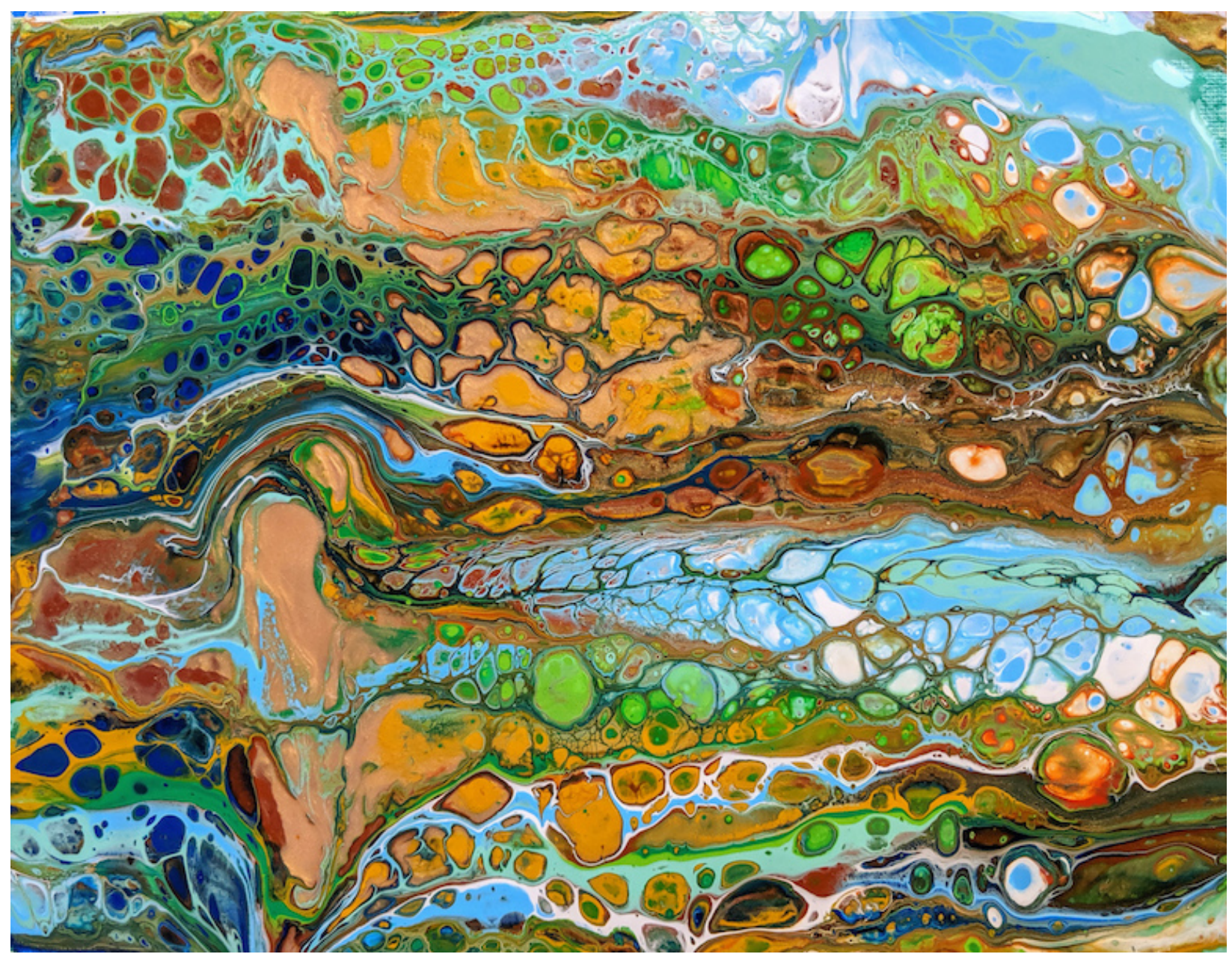

Fig. 2. Collaborations with Algae image still. (C Juniper Harrower. Photo: Juniper Harrower.)

Reverberating Futures by artist Fiona Hillary is an immersive sound and film work that explores human and non-human entanglements to generate wonder and create a unique space for contemplation with our algal kin (Fig. 3). By abstracting ordinary experiences, it encourages audiences to encounter the possibility of recuperation in the age of the Anthropocene. The southern hemisphere is currently experiencing unprecedented occurrences of algal drift across the ocean ${ }^{1,3}$. Appearing as red tides during the day, locally occurring bioluminescent dinoflagellates, Noctiluca scintillans, glow blue in the evenings' crashing waves. They are nomadic and non-motile - they rely on the wind and the tide to move. Their glow works on a circadian rhythm, a 24-hour internal clock. They have a flagellum that extends from their cell 
Harrower, The Algae Society BioArt Design Lab: Exploring multispecies entanglements and making kin with algae

May 19, 2021

scooping phytoplankton, nutrients, and other algae from the water as food. They require carbon and emit oxygen and are a useful bioassay tool to detect pollutants in water, like nitrogen, a common effluent of urbanization and industry. Reverberating Futures brings together imagery collected from laboratory-grown dinoflagellate cultures, Noctiluca scintillans and Pyrocystis lunula, and fieldwork recordings from the Western Treatment Plant in Werribee and from Port Philip Bay in Victoria, Australia, while speculating on the sound of dinoflagellates. Learning to culture and live with bioluminescent dinoflagellates in the laboratory and field promotes a connection to and understanding of algae as kin. By documenting Noctiluca and other dinoflagellates through image, sound, and film, and creating digital representations of the research process, viewers and researchers have access to a unique platform to consider the effect of algal blooms and what the blooms may actually mean. View Reverberating Futures here: https://vimeo.com/371961078

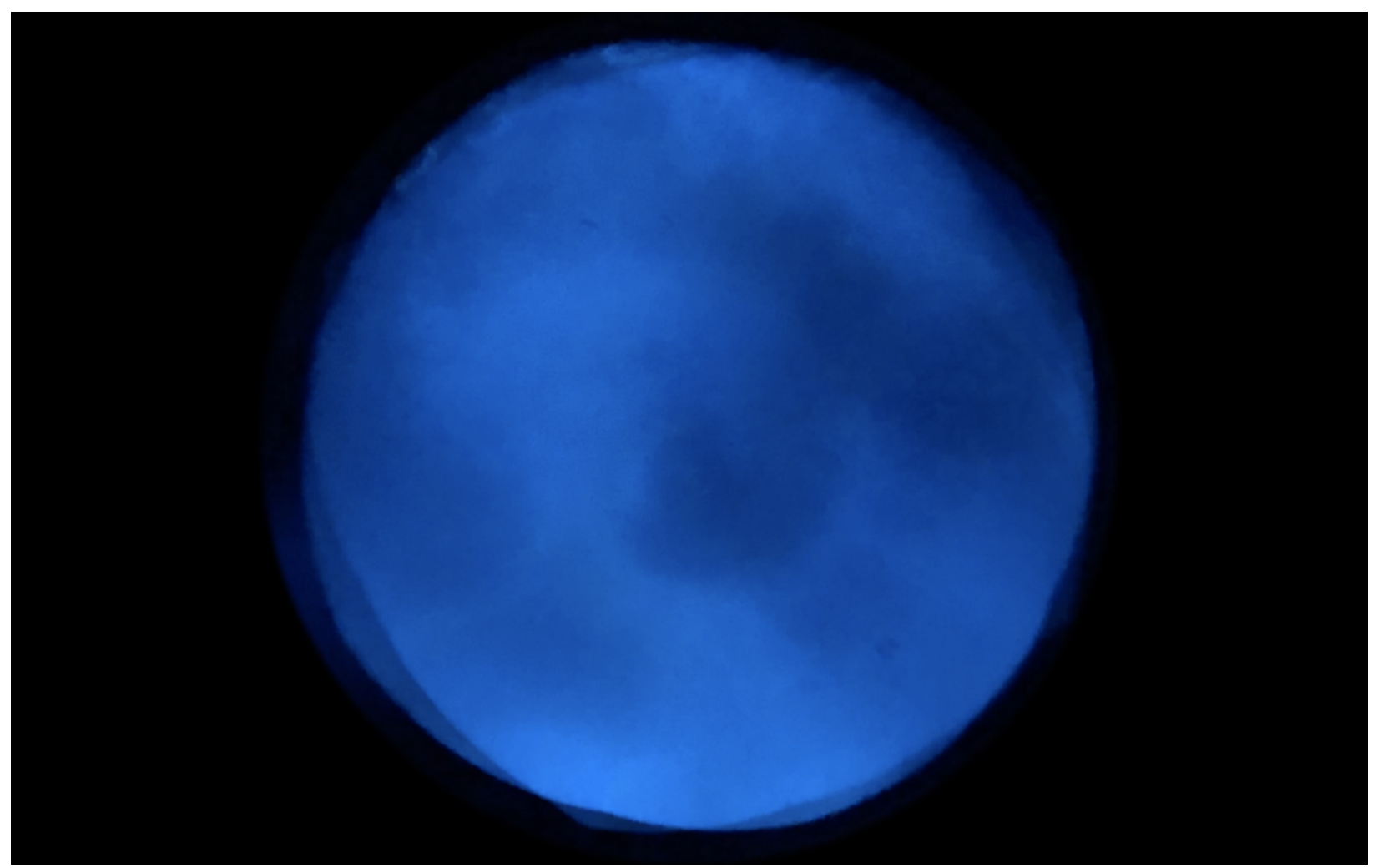

Fig. 3. Reverberating Futures image still. (C Fiona Hillary. Photo: Fiona Hillary.) 
Harrower, The Algae Society BioArt Design Lab: Exploring multispecies entanglements and making kin with algae

May 19, 2021

Bleaching Pocillopora by artists José Carlos Espinel and David Harris is a multimedia installation investigating coral bleaching and revival simulations based on Great Barrier Reef bleaching event data (Fig. 4). Coral reefs are some of the most diverse algal ecosystems in the world $^{1}$. They protect coastlines from storms and erosion, are a source of food and medicine, and provide livelihoods for local communities. Climate change is the greatest global threat to coral reef ecosystems, as warmer water temperatures can result in widespread coral bleaching ${ }^{2}$. As the water warms, corals will expel the algae (zooxanthellae) living in their tissues, causing the coral to turn completely white. Corals can survive a bleaching event but will be under increased stress with a higher likelihood of mortality. As temperatures rise, mass coral bleaching events and infectious disease outbreaks have become more frequent ${ }^{1}$. Over time, the cumulative bleach and revival cycles lead to permanent bleaching of the reef and death to the algae and other organisms that live there. Bleaching Pocillopora uses Pantone's 2019 Color of the Year "Living Coral" as a projection to show the bleaching of the coral with a revive in cycles mimicking (Great Barrier Reef) data of coral bleaching events - each revival never fully recovering. The artist created coral is cast in plaster as a modular relief of 9x9 inch tile-like pieces, created from 3D prints based on underwater photogrammetry models. The 10-minute video illumination evolves from a rich color to a bleached white as the symbiotic relationship between coral and the algae that provide the characteristic color is disrupted. This installation provides viewers an opportunity to engage with the complex data by distilling and simplifying it into a quiet moment that prompts reflection for this epic loss. 
Harrower, The Algae Society BioArt Design Lab: Exploring multispecies entanglements and making kin with algae

May 19, 2021

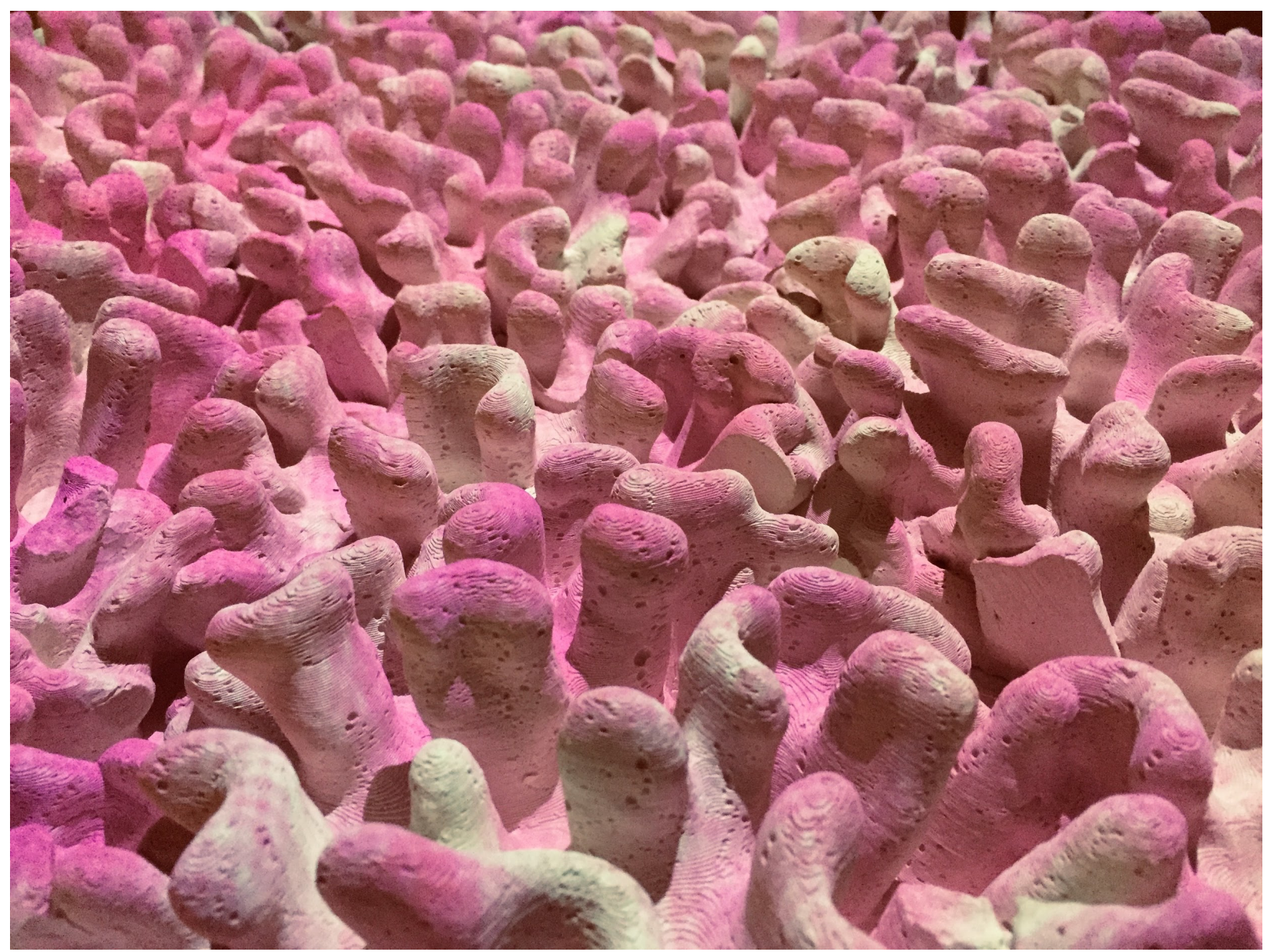

Fig. 4. Bleaching Pocillopora. (C José Carlos Espinel and David Harris. Photo: José Carlos Espinel.)

Cyanovisions by artist Tiare Ribeaux in collaboration with Jody Stillwater, is a transdisciplinary project that explores deeper narratives related to human identity, kinship with other species, and our changing environment in an era of climate change (Fig. 5). This project combines video, installation, and bioart, to focus on cyanobacteria (blue-green algae). These algae were the first organisms on our planet to photosynthesize and produce the oxygen that created our current atmosphere $^{2}$. Humans generate pollutants that cause aggregations of toxic cyanobacteria blooms $^{3}$, yet we also create new life forms through synthetic biology, genetic engineering, and artificial life. As an alternative narrative to the dominance over nature that cyborgian hybrid immortality offers, Cyanovisions posits potentials for biological hybridity and scientific 
Harrower, The Algae Society BioArt Design Lab: Exploring multispecies entanglements and making kin with algae

May 19, 2021

spiritualities that recognize the inextricable relationship of human lifespans to those of other organisms. Cyanovisions moves beyond revealing correlations of human, natural, and sterile engineered forms. It merges the human body and the most fundamental and ancient life force, Light Energy, and the ancient organism cyanobacteria. Speculative mutualisms of the future are revealed showing humans living in symbiosis with nature and cyanobacteria in scenarios that are peaceful, disturbing, and surreal. View Cyanovisions at:

http://www.tiareribeaux.com/cyanovisions

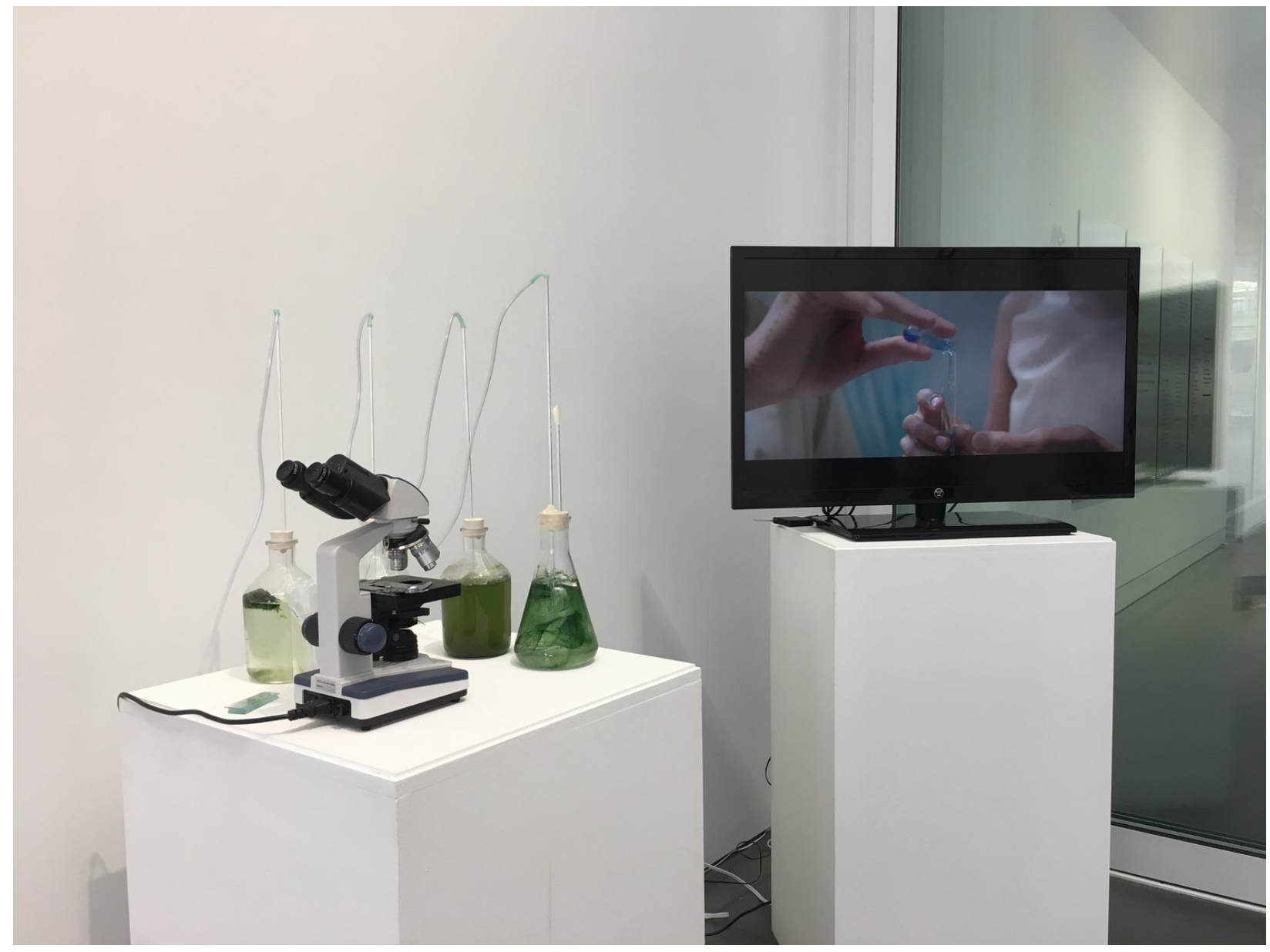

Fig. 5. Cyanovisions installation view. (C) Tiare Ribeaux. Photo: Tiare Ribeaux .)

By creating various social spaces in which humans can encounter algae, these exhibitions aim to bring a greater appreciation for algae and other non-human species. Embedded in a social context, the Algae Society is able to explore beyond issues of the environment and ecology to 
Harrower, The Algae Society BioArt Design Lab: Exploring multispecies entanglements and making kin with algae

May 19, 2021

social, cultural, and non-human justice; local, regional, and global community; and speculative futures with new kinds of multispecies entanglements.

Through these provocative explorations and interactive installations, we find that art and science together can connect people in personal and transformative ways. By promoting different methods of knowing and conceptualizing algae, hopefully we can empower new directions for research, public engagement, and community action. As arts researchers, we promote this important message but have also found growth through these interdisciplinary interactions that prompt consideration of how we approach research within our arts practices.

To continue developing and better understanding our kinship with algae, we are interested in finding methods of interaction that will allow us to explore the agency of algae in the artworks more deeply. We are experimenting with how we can move beyond merely engaging with algae in our work as a tool to think with (or model organism), and are actively seeking to form more collaborative practices, or as Karan Barad challenges us, to not just consider species in terms of their usefulness, but to think with them while understanding that these are real living beings and that we have an ethical obligation to them ${ }^{10}$. With this focused attention we can avoid misrepresenting algal properties while also seeking better ways to share algal stories that stretch beyond human-driven narratives. However, we also wonder if collaborating and co-creating with algae is actually possible given that algae cannot consent? We will continue to unpack this question more thoroughly with our ongoing practices as we consider the many complexities of conceptualizing agency, building kinship, and visualizing multispecies worldings. In September 2021, we open Confluence, a large-scale algal art exhibition at the Cameron Art Museum, running through April 2022. This exhibition will highlight new work from the Algae Society that explores speculative futures and further investigates what it means to build kinship with algae and the local human community. 
Harrower, The Algae Society BioArt Design Lab: Exploring multispecies entanglements and making kin with algae

May 19, 2021

\section{References}

1) Doney, S.C., Busch, D.S., Cooley, S.R. and Kroeker, K.J., 2020. The impacts of ocean acidification on marine ecosystems and reliant human communities. Annual Review of Environment and Resources, 45, pp.83-112.

2) Chapman, R.L., 2013. Algae: the world's most important "plants" — an introduction. Mitigation Adaptation Strategies for Global Change, 18, 5-12.

3) Cloern, J.E., 1996. Phytoplankton bloom dynamics in coastal ecosystems: a review with some general lessons from sustained investigation of San Francisco Bay, California. Reviews of Geophysics, 34(2), pp.127-168.

4) Morsink, K. With every breath you take, thank the ocean. Smithsonian: https://ocean.si.edu/ocean-life/plankton/every-breath-you-take-thank-ocean. Accessed online May 13, 2021.

5) Haraway, D. J., 2016. Staying with the trouble: Making kin in the Chthulucene. Duke University Press.

6) Harrower, J., Parker, J. and Merson, M. 2018. Species loss: Exploring opportunities with art-science. Integrative and comparative biology, 58(1), pp.103-112.

7) National Academies of Sciences, Engineering, and Medicine. 2018. The integration of the humanities and arts with sciences, engineering, and medicine in higher education: Branches from the same tree. National Academies Press.

8) Demos, T.J., Scott, E.E. and Banerjee, S. eds., 2021. The Routledge Companion to Contemporary Art, Visual Culture, and Climate Change. Routledge.

9) Espinel J., Parker J., Espinel-Velasco N. 2020. Science and Collectivism in Artistic Creation: Embracing Climate Change through Art. The International Journal of the Arts in Society: Annual Review. Volume 14, Issue 1:12-20.

10) Barad, K., 2012. Nature's Queer Performativity. Women, Gender \& Research (12): $25-52$. 